\title{
SOBRE ÁRBOLES Y PERSONAS: LA PRESENCIA DEL ROBLE (NOTHOFAGUS OBLIQUA) EN LA VIDA CORDILLERANA MAPUCHE DE LA CUENCA DEL RÍO VALDIVIA
}

\author{
ON TREES AND PEOPLE: THE PRESENCE OF THE OAK \\ (NOTHOFAGUS OBLIQUA) IN THE ANDES MOUNTAIN LIFE \\ OF THE MAPUCHE PEOPLE IN THE VALDIVIA RIVER BASIN
}

\section{JUAN C. SKEWES*, DEBBIE E. GUERRA*}

\section{RESUMEN}

La presencia del roble (Nothofagus obliqua) en la vida cotidiana y ritual del pueblo mapuche ha sido obviada en la literatura especializada. No obstante, hay en el acervo cultural mapuche una identidad profunda entre persona y árbol, identidad que merece atención y que demanda la colaboración transdisciplinaria para su estudio. La adopción de esta perspectiva permite redescubrir una relación a través de la que puede entenderse el protagonismo de una especie arbórea en un ámbito de incuestionable trascendencia cultural como es la muerte. El roble se vuelve protagónico en tres momentos rituales funerarios: en los wampos o canoas que sirven de urna fúnebre, en el chemamull o escultura recordatoria y en los descansos o hitos hogareños de encuentro con los difuntos. Al situar el foco del análisis en la especie se pueden, además, reposicionar en el marco de la historia ambiental las relaciones que se dan entre mapuches y chilenos en contextos de permanente transformación territorial y en los que coexisten otras contradicciones como son las que se dan entre especies arbóreas que articulan los proyectos económicos y culturales que animan a los diversos grupos de interés que ocupan el territorio. Finalmente se subraya la necesidad de asumir estas perspectivas a fin de subsanar omisiones importantes en la literatura especializada acerca de prácticas culturales cuyos contenidos materiales suelen ser obviados.

Palabras clave: Historia ambiental, cultura mapuche, bosque, roble (pellin).

* Ph.D. Antropología, Universidad Alberto Hurtado, Departamento de Antropología. Santiago, Chile. Correo electrónico: jskewes@uahurtado.cl

** Antropóloga, candidata a Doctora, Universidad Austral de Chile, Centro de Estudios Ambientales e Instituto de Salud Sexual y Reproductiva. Valdivia, Chile. Correo electrónico: dguerra@ uach.cl 


\section{ABSTRACT}

The Chilean oak tree (Nothofagus obliqua) presence in the Mapuche everyday and ritual life is scarcely addressed in the specialized literature. However there is, in the Mapuche cultural background, a strong identification between person and tree, an identity that deserves attention and transdisciplinary collaboration for its study. The adoption of this perspective allows us to rediscover a relationship that explains the relevance of this tree species in a context of unquestionable cultural transcendence in the rituals of death. The roble (oak) becomes prominent in three moments of the funerary process: in the disposal of the dead in a funeral canoe or wampo made out of roble (oak), in the chemamull or wooden sculpture made out of the same wood, and in the descansos or domestic altars built by a roble (oak) where interactions between the living and the dead take place. In focusing the analysis on the species of roble, the relations between Mapuche and Chileno gain renewed prominence in terms of environmental history. Faced with permanent reorganization of the land, new conflicts arise among different interest groups whose cultural projects are articulated around tree species. Finally, the need of addressing issues that are understudied is stressed, contributing to improve current understanding of cultural practices that have important material dimensions.

Keywords: Environmental history; Mapuche culture; woods; Chilean oak tree - roble (Nothofagus obliqua or pellín).

Recibido: 17.05.13. Aceptado: 03.12.13.

\section{INTRODUCCIÓN}

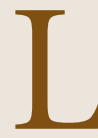

A VIDA DE LAS PERSONAS en buena parte determina la vida de los árboles y, al menos en términos gruesos, ésta influye en la vida de las comunidades y seres humanos. Árboles y personas transitan por avenidas que a menudo se entrecruzan y, a lo largo de la historia, la relación se ha invertido: de huéspedes en bosques, los humanos tienden a convertirse en depredadores (Pogue, 1992). Si en otros escenarios los seres humanos habitaron los claros y merodearon entre los ríos y meandros de las zonas boscosas, hoy son los árboles los que suelen albergarse en ciudades y pueblos, en plazas principales, jardines, reservas naturales y zonas de conservación. La relación no siempre tiene o tuvo este carácter polar ni por norma constituyó un ejercicio de fuerzas donde la presencia de unos, los humanos, significaba la depredación de los otros, los árboles. El bosque como amenaza, la naturaleza verde que devora todo lo que descuida el ser humano y el orgullo de éstos al establecer sus praderas y cultivos, son parte de una cosmovisión agrícola, primero, e industrial, después, que da cuenta de economías intensivas cuyos nutrientes deben ser extraídos y separados de los paisajes más complejos de los que son parte para transferir su potencia a los humanos que pasan a 
depender de ellos (Pogue, 1992). La roza y quema y la roturación de los campos dan cuenta de una cultura territorializada de modo excluyente: a fuerza de fuego los árboles son ahuyentados de las planicies y de las zonas de cultivo, como desde la Colonia en adelante ocurrió al centro y sur chilenos (Elizalde, 1968). Los árboles se doblegan ante la voluntad humana de extraer de la tierra granos y pastos y entregan su anatomía para el servicio de la leña, de la madera y de la producción papelera. Y también se dejan domesticar para alimentar a estas industrias: la plantación forestal pasa a sustituir al bosque no sólo en la tierra pero también en la imaginación ciudadana que simboliza a través del pino (Pino radiata) la naturaleza de la que se cree parte.

Las conversaciones entre los seres humanos y los árboles son parte de tradiciones de largo aliento. Tales conversaciones pueden ser seguidas, como intentamos hacerlo aquí, a través de especies que han tenido un papel estructurante en la relación que los seres humanos han establecido con su entorno. Y no sólo con los seres humanos sino que más bien las culturas han advertido en tales especies el papel estratégico que desempeñan en la conservación, reproducción y perpetuación de los ecosistemas locales $(\mathrm{Ga}-$ ribaldi y Turner, 2004). La especie hace aquí las veces, por una parte, de testigo clave de una historia no contada del paisaje de la que es parte, y, por la otra, de soporte de procesos ecológicos a través de los que se nutren otros seres vivos. En nuestro caso nos ocupamos de una especie en particular cuyo diálogo con los seres humanos no se ha hecho notar en demasía en la literatura científica. Es la relación entre el roble o coyan (Nothofagus obliqua), las comunidades mapuche y los paisajes cordilleranos del sur de Chile, y más particularmente, de la zona cordillerana aledaña a los lagos Calafquen, Neltume y Panguipulli. La elección de esta especie no se da al azar. Al estudiar la referida zona, el roble, amén de su presencia física, aparece con una inusitada intensidad en la vida social y ritual de las comunidades mapuche cordilleranas, a pesar de lo cual la antropología no resulta especialmente generosa en esta materia. Los robles son simultáneamente testigos de la tradición maderera que movilizó los intereses comerciales chilenos tanto como proyectos y utopías políticas ligadas a la formación de un proletariado maderero. Su presencia se hace sentir en las culturas locales que son parte de este territorio. Se infiltra en la materialidad de la vida cotidiana bajo la forma de leña, material de construcción para la vivienda o de objetos de uso cotidiano. A nivel ritual, los árboles se tornan especialmente relevantes y, entre los que pueblan la cordillera y la depresión intermedia, los robles se destacan por sus asociaciones fúnebres en la cultura mapuche, como veremos más adelante. 
Para dar cuenta de estas conversaciones hemos procedido a indagar, a través del trabajo de campo realizado entre los años 2009 y 2011, acerca de la presencia arbórea en las palabras y prácticas cotidianas y rituales del mundo mapuche enclavado en la zona cordillerana correspondiente a las actuales comunas de Panguipulli y Lanco en su sector oriental, tomando como referencia las comunidades del lago Neltume y de Milleuco. Para hacerlo hemos recurrido a la observación y al análisis de contenido tanto del material documental disponible como de los registros de sonido generados por la vía de entrevistas y grupos de discusión realizados en estas comunidades habitantes de la porción septentrional media y superior de la cuenca del río de Valdivia. Tal procedimiento nos abre el mapa mental de las y los lugareños, al tiempo que por medio de la observación directa y participación en algunas actividades sociales y rituales hemos podido constituir las referencias contextuales en las que se deben situar las relaciones entre seres humanos y árboles.

A objeto de contribuir a contextualizar con mayor amplitud el caso de nuestro interés, ilustraremos el lugar de las especies arbóreas en las luchas religiosas y en los procesos históricos con ejemplos tomados de otras latitudes. Esta digresión se justifica toda vez que permite situar al lector o lectora -ajeno en muchos casos a las realidades locales que se discuten en lo que sigue- en su propia realidad y entender a partir de sus circunstancias las dimensiones y aspectos abordados a continuación. El texto continúa con una breve revisión de la botánica sagrada del mundo mapuche para luego examinar la presencia del roble en la vida social y ritual tal cual se expresa a través de las palabras y prácticas que hemos registrado enfatizando la identidad que se establece entre esta especie y los seres humanos y el papel regenerador de la vida que se mediatiza a través de los robles.

Este estudio demuestra la necesidad de desplazar la mirada desde la agencia humana considerada aisladamente hacia el protagonismo que otras especies tienen en la configuración de los hechos históricos. La revisión de una vasta literatura acerca de la cultura mapuche da cuenta de una omisión transversal: la de una especie arbórea situada en el eje articulador no sólo de la vida y de la muerte sino que también del encuentro y, sobre todo, desencuentro, de los pueblos mapuche y chileno.

\section{LUCHA DE PUEBLOS, LUCHA DE ESPECIES Y LUCHA DE CLASES}

Los árboles no son indiferentes a los sistemas culturales a través de los que adquieren sus significados. Mircea Eliade (1979) propone una cierta uni- 
versalidad del simbolismo asociado a los árboles, universalidad que convendría matizar sin soslayar el hecho de constatarse la presencia de una imaginación arbórea en la mayoría de las culturas conocidas. Más que profundizar en una discusión acerca del simbolismo arbóreo y la diversidad cultural, nuestra propuesta lleva a especificar las relaciones que se establecen en torno a determinadas especies arbóreas. A diferencia de la poesía, la mirada de las ciencias sociales no siempre ha sido generosa con la identificación de estas especies arbóreas, dejando con ello escapar ricas posibilidades de interpretación. Tales posibilidades, como sugerimos, entrañan dimensiones religiosas, políticas y económicas que bien pueden interpretarse en el marco de una ecología política de los árboles.

Tres ejemplos permiten ilustrar esta aproximación. El primero de ellos concierne al uso del pino (Pinus sylvestris) en la Navidad cristiana, árbol que da cuenta de una historia que ilustra y contextualiza los conflictos que nos ocupan. La acción misionera de San Bonifacio, Patrono de Alemania (aunque inglés de nacimiento), en los inicios del siglo XVIII, procura desterrar el árbol sagrado -roble (Quercus) - a través del que las tribus germanas adoraban a Thor. Según la creencia popular, cuando se preparaba un sacrificio humano, de un hachazo cortó el árbol sagrado, empleando la madera para levantar una Iglesia en homenaje a San Pedro (Parachin, 2012). El símbolo dominante de la religión germana -de acuerdo a la terminología de Turner (1999)- se convierte en uno instrumental para la difusión de la fe cristiana. El árbol escogido -un pino oregón o abeto de Douglas (Pseudotsuga menziesii)- caracterizado por la predominancia de formas triangulares no deja de ser evocativo del dogma cristiano de la Santísima Trinidad. La historia, con mucho de folklore, habla de la conflagración religiosa y de la instrumentalización de los símbolos, pero también del matiz utilitario que a través de ella se introduce, trocando los árboles en madera y en elementos decorativos en la celebración de la Navidad. La instauración del árbol como símbolo de esta fiesta se asociará, a su vez, a un fuerte énfasis nacionalista especialmente en Alemania, primero, y en Inglaterra, después (Armstrong, 2008).

Las connotaciones políticas del uso de los pinos adquieren una mayor precisión en la breve pero decidora narración de James C. Scott (1998) acerca del origen de las ciencias forestales en Prusia y Sajonia al finalizar el siglo XVIII (ver también, Pogue 1992). Lo que allí se buscaba era ejercer control sobre los bosques y facilitar su inclusión territorial y comercial a un Estado en su proceso de consolidación. La generalización de un árbol estándar para el desarrollo de las plantaciones forestales fue la gran conquista 
que permitió la uniformización del bosque y, con ello, su administración centralizada y explotación comercial. El rediseño del bosque se tradujo en ventajas indiscutibles para el Estado: las hileras paralelas de árboles facilitaban la vigilancia; la producción podía ser administrada sobre la base de planes a largo plazo y proveía de un suministro constante y uniforme de materia prima, y se evitaban las fluctuaciones tributarias.

La reorientación del uso de los bosques es un tercer ejemplo que proporciona Carlos Marx al denunciar la expoliación a los campesinos de Escocia. La burguesía de la época se da a la caza y, en ausencia de bosques en Inglaterra, se convierte a Escocia en el último asilo de aquella "noble pasión". "Los montes de caza son incompatibles con la gente", dice Marx (1984, p. 917), y citando a Somers (1848) sugiere que "si los cotos de caza siguen creciendo en las mismas proporciones que en el último cuarto de siglo, no quedará ni un solo escocés en su tierra natal". Las valiosas creaciones del trabajo, escribe Somers $(1848$, p. 25) a su vez, son extirpadas para que el ciervo goce el lujo de la soledad y los cazadores monopolicen los placeres de la caza.

En Chile, la acumulación propiamente capitalista asociada a la explotación de las maderas será posible toda vez que la domesticación de los árboles ha tenido lugar y, junto con ello, el desarrollo de vastos mercados para el papel y la madera (Pogue, 1992). Un nuevo enfrentamiento de especies se asocia a semejante expansión: el pino radiata (Pinus radiata) y el eucaliptus (Eucalyptus globulus) se tornan en depredadores del suelo y del agua que nutren a las especies nativas. Las tecnologías para la explotación y para el transporte, sumadas a la escala de los negocios, serán las condiciones previas para dar el salto de explotaciones mercantiles a explotaciones industriales de la madera.

\section{VERSIÓN LOCAL DE CONFLICTOS GENERALES}

Los conflictos surgidos al interior de la cuenca del río Valdivia a partir de 1898 asociados a la expansión capitalista fueron factores decisivos para la reorganización del territorio mapuche cordillerano de la actual región de Los Ríos, lo cual no impidió la resiliencia de una cultura que, como los árboles que le acompañan, se caracteriza por su porfía frente a las catástrofes. Para el mundo mapuche, la cordillera representa un territorio sagrado cuyas interconexiones son mediadas por árboles, cursos de agua y por la fuerza trascendente de los volcanes. Allí se acumulan las pisadas de generaciones y generaciones de seres humanos que oraron a las aguas y conversaron con difuntos cuyos recuerdos se anclaron en los árboles. Las 
comunidades chilenas, en cambio, llegaron a las cordilleras movidas ya no por árboles sino que por la madera que de ellos podía obtenerse. No deja de llamar la atención que, de todas las especies arbóreas del monte, sean el coihue (Nothofagus dombeyi), el raulí (Nothofagus alpina) y el mañío (Podocarpus salignus) las más promovidas por su valor comercial en las propuestas de explotación de los bosques de segundo crecimiento (Grosse, Larraín, y Mujica, 2007).

La ocupación territorial de la cuenca del río Valdivia fue más bien tardía y estuvo fraguada por el fraude (Klubock, 2011; Loveman y Lira, 2001). En el caso de Panguipulli, el gobierno chileno entregó, en 1898, la concesión del territorio a la compañía Camino Lacoste para colonizarlo: a menos de una década, el inspector general de Colonización encuentra que lo que menos hay son colonos (Rehren, 1908). El vasto territorio se convierte así en sitio de explotaciones forestales que atraen trabajadores madereros. Los años cincuenta del siglo veinte dan cuenta de una incipiente industrialización de la actividad forestal con la instalación de aserraderos mecánicos y la producción de bienes derivados de la madera (Alarcón, 1958).

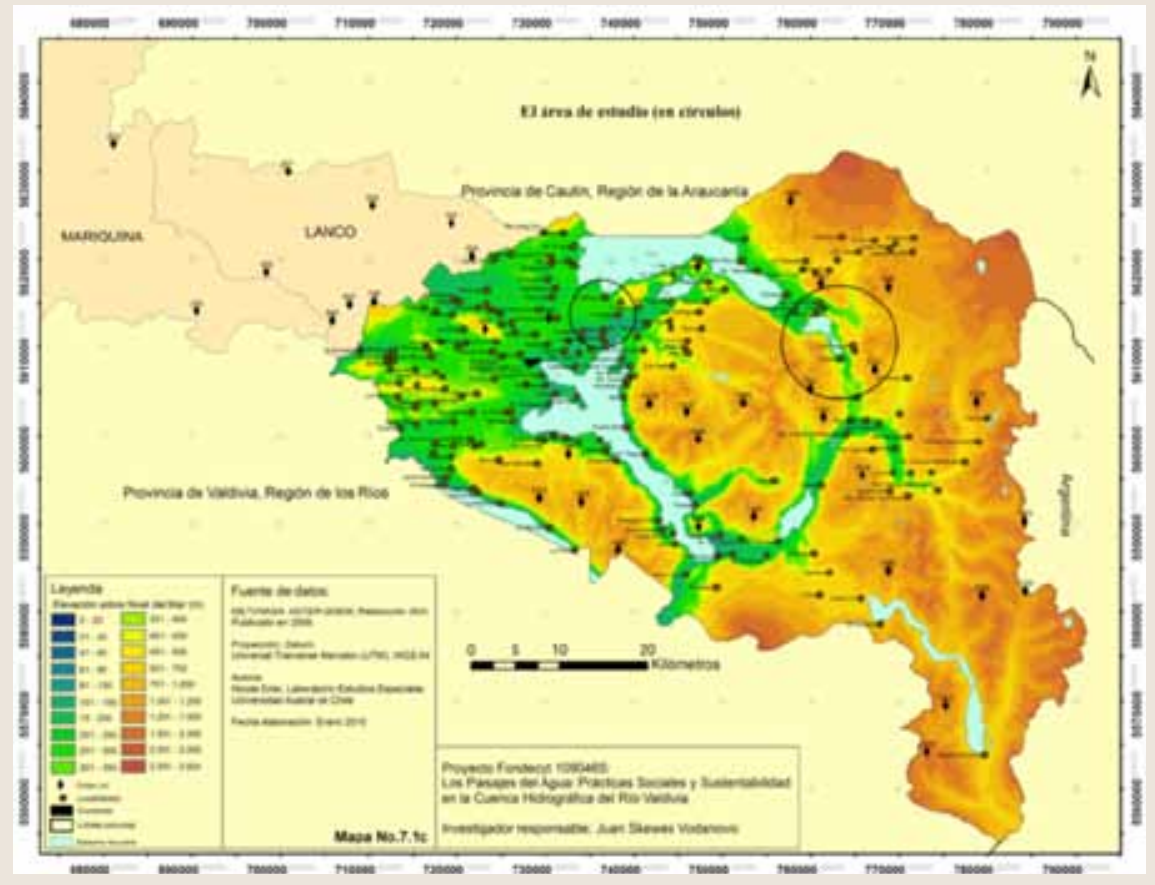

Figura 1. El área de estudio (elaboración propia). 
El Complejo Maderero e Industrial Panguipulli, creado en el gobierno de Salvador Allende a partir de la expropiación de 13 fundos cuya propiedad es irregular, encarna un proyecto socialista de explotación forestal. La madera se transforma en un objetivo de Estado y 3.600 trabajadores se allegan al territorio bajo el alero de la Corporación de Fomento de la Producción (Rivas, 2006). La breve existencia de un proletariado maderero marcó la memoria de un modo diametralmente opuesto al que inspira a las comunidades mapuche, lo que llevó incluso a conflictos por ocupación de tierras indígenas por parte de obreros madereros en los límites meridionales del complejo (Guerra, Barrientos, y Ramírez, 1999).

Al descarnado capitalismo mercantil y a la utopía del socialismo maderero suceden transformaciones derivadas de la globalización asociadas a la apropiación de los recursos naturales por grandes consorcios financieros transnacionales. Lo que Alonso de Góngora y Marmolejo describiera como "las mejores aguas que se cree haber en el mundo" se convierte en objetivo comercial para empresas generadoras de electricidad. A tales proyectos se suman los nuevos cotos de caza trocados ahora en paraísos turísticos o campos de recreación para magnates chilenos. Son los nuevos referentes para la reorganización territorial del interior de Panguipulli y, como es de costumbre, los pobladores rurales mapuche se convierten en víctimas de la voracidad financiero-comercial (Skewes, Guerra, Rojas, y Mellado, 2011).

\section{LA CORDILLERA MAPUCHE}

Los bosques son frutos de la historia. Su composición, las especies que los habitan y sus relaciones recíprocas resultan de procesos dinámicos de reacomodo frente a circunstancias cambiantes y de la acción de los propios seres humanos, como en el caso del cerezo trasplantado a Europa por obra del comercio, según se anota en La ideología alemana (Marx y Engels, 2005). El interior cordillerano de la cuenca del río Valdivia no es ajeno a la acción humana. Prima allí, en calidad de bosque secundario, el tipo forestal roble (Nothofagus obliqua) -raulí (Nothofagus alpina) - coihue (Nothofagus dombeyi), combinación de especies que responde a las transformaciones históricas de los últimos siglos derivadas de la acción combinada del ser humano y de las catástrofes naturales (Lara, Solari, Prieto, y Peña, 2012; Solari, Cueto, Hernández, Rojas, y Camus, 2011; Donoso, 1993). 


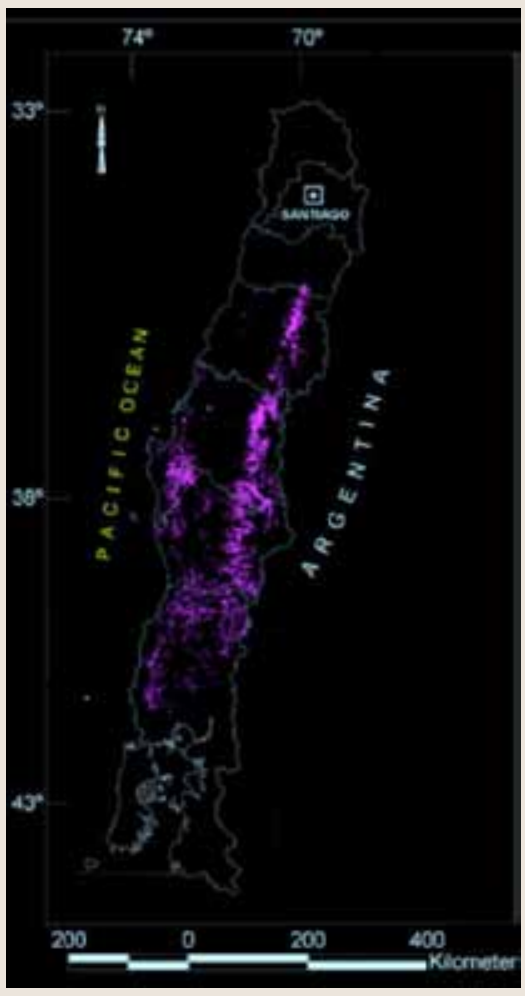

Figura 2. Distribución del tipo forestal robleraulí-coihue (adaptado de Neira, 2012).

Entre las especies protagónicas del bosque mapuche está el roble (Nothofagus obliqua) cuyo interés cultural queda de manifiesto en la proliferación de nombres que se le asocian (coyán, hualle, pellín, además de roble y Nothofagus). El protagonismo de esta especie trasciende las escalas históricas y se inmiscuye en las eras geológicas de las que ha sido testigo. Su biogeografía validaría, según algunos autores, la secuencia de desprendimiento de Gondwana (Swenson, Hill, \& McLoughin, 2001) y, según otros, representaría una irradiación post-Gondwanana que habría comenzado entre 55 y 40 millones de años atrás (Lyn G. y Michael D., 2005). Cualquiera fuera el escenario, no cabe duda de la milenaria presencia de los robles en la conformación arcaica del territorio. 
A pesar de su antigüedad en el planeta, cuesta a la mirada hegemónica occidental reconocerlo. Lo que el Conquistador observa le recuerda a la haya (Fagus sylvatica), el fagus verdadero, si se quiere. Lo que tiene ante sus ojos no puede aspirar sino a ser un nothofagus, una falsa haya según lo denota el prefijo latín. Se trata de una imagen construida desde fuera y por negación: son árboles americanos que semejan las hayas europeas pero que no lo son. El verbo del español, como lo subraya Krotz (2004), se torna impotente frente a una naturaleza que lo desborda.

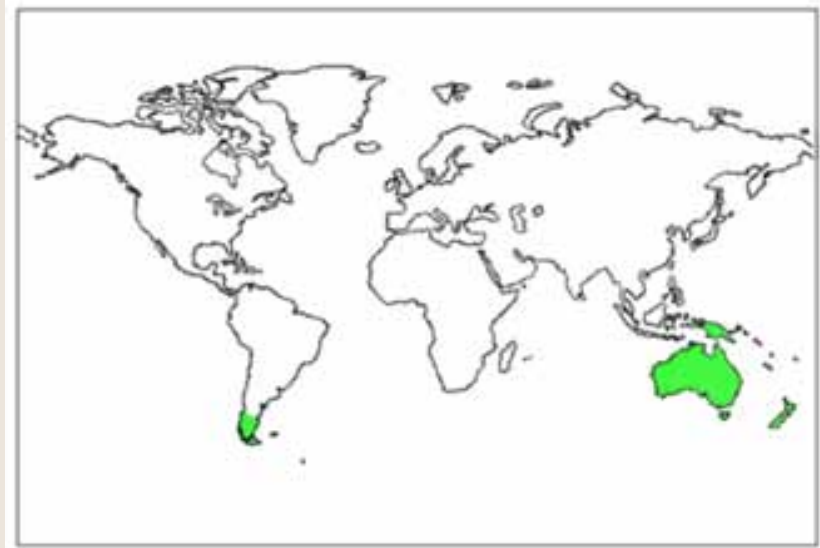

Figura 3. Distribución del Nothofagus a escala mundial (a partir de Heads, 2006).

Los robles chilenos son árboles de gran tamaño que también alcanzan las mayores alturas en los bosques donde viven. Pierden sus hojas en el otoño y, entre enero y marzo, se encuentran sus frutos. Sus flores son pequeñas, unisexuales, dispuestas en inflorescencias; las masculinas rodeadas por un perigonio formado por cinco a siete lóbulos y treinta y cuarenta estambres y las flores femeninas se reúnen en grupos de a tres, forma de agrupamiento que recuerda las prácticas de poliginia y poliginia sororal que se dieron en la sociedad mapuche (Donoso, 2007 [2005], pp. 90-1). 


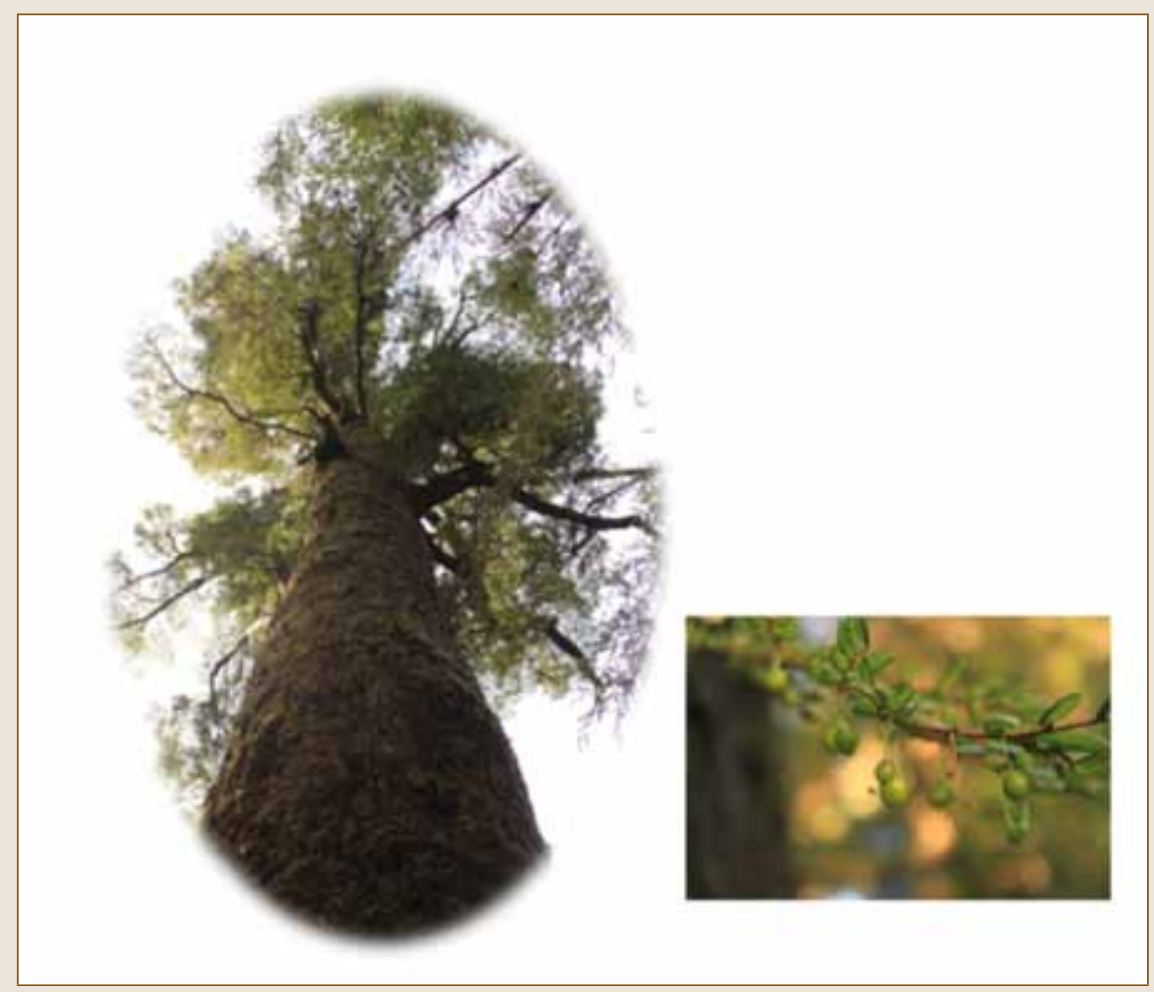

Figura 4. Pellín y floración (foto de L. Skewes).

Los robles se encuentran entre Santiago (en el Cerro La Campana y en Las Vizcachas) y Chillán en los bosques de altura, y entre Chillán y Llanquihue son preponderantes en la depresión intermedia y faldeos cordilleranos. La especie tiende a restringirse a sitios que son climatológica y edafológicamente sub-óptimos o a sitios expuestos a perturbaciones de carácter catastrófico recurrentes (Read \& Hill, 1985). Aunque los Nothofagus están mejor preparados que las demás especies del bosque húmedo para soportar condiciones especialmente adversas, sus semilleros son competidores más bien pobres (ibíd). 


\section{EL ROBLE EN LA CULTURA MAPUCHE}

A pesar de su presencia omnisciente, los robles han encontrado pocas referencias en la literatura antropológica acerca del pueblo mapuche. De mayor interés han sido aquellas especies emblemáticas que por su papel en la vida ritual o por sus características únicas han despertado el interés y curiosidad de las y los investigadores: el canelo (Drimys winteri), la araucaria (Araucaria araucana) y el alerce (Fitzroya cupressoides), a los que la literatura ha dedicado bastante espacio. Más allá de la mayor o menor frecuencia de las referencias literarias, las especies arbustivas y arbóreas son permanentemente incorporadas en las prácticas sociales y rituales del mundo mapuche.

El rehue (lugar sagrado) se compone de diversos vegetales como el maqui (Aristotelia chilensis), el canelo (Drymis winteri), la quila (Chusquea quila), el manzano (Pyrus malus) y el helecho ampe (Lophosoria quadripinnata). En medio de estas ramas se coloca un palo con peldaños (el rehue estrictamente dicho) para que en él se extasíen las machis. Excavan un hoyo, echan adentro pesos y chauchas de plata y plantan sobre estas monedas el (palo) rehue (Pascual Coña, en Moesbach, 1930, p. 342).

En el nguillatún toman su lugar además la luma (Amomyrtus luma) con las que se hacen las macanas, el raulí (Nothofagus alpina) o el canelo como árbol ceremonial, mientras que los palos de maqui joven se usan para hacer la carne, y lo coligües (Chusquea culeou) para cubrir los rukos o viviendas para el tiempo ceremonial (Olivares, 2010). "El coligüe también es importante", comparte un interlocutor, "éstos no fallan, son los principales cuando se va a hacer un machitún. La gente se preocupa de encontrar un coligüe bueno, largo, bonito, derecho si es posible".

El uso ritual y ceremonial de las especies arbustivas y arbóreas constituye un freno cultural a la depredación, una suerte de regulador social de la intensidad en la explotación de estas especies (Grebe, 2000). De allí que los paisajes resultantes de tales actividades tienden a conservar un significativo número de especies que tienen un carácter estructurante de la ecología local (Garibaldi \& Turner, 2004).

El roble no tiene participación directa en la vida ceremonial salvo como lugar de encuentro en la preparación del nguillatún o rogativa comunitaria y en los ritos fúnebres, lo cual resulta crucial. En la vida cotidiana, el roble es fundamental tanto para la provisión de leña como para la construcción y la confección de instrumentos de uso diario, además de proveer alimen- 
to: “Todos apreciaban los dihueñes, que crecen en los robles", se señala en Moesbach (1930). En terreno recogimos un testimonio en que la persona recuerda haber comido el corazón del pellín: "El corazón, que es como blanco, nosotros años atrás, cuando nosotros teníamos ocho o nueve años, y donde mi papá habían de esos pellín grande y con su corazón nuevecito, y como uno es niño comíamos nosotros, si eso no le cuento nada a mis hijos".

$\mathrm{Al}$ igual que sus congéneres humanos en la cultura mapuche, los robles -y también los coihues- reconocen dos edades: la joven, el hualle, y la madura, el pellín (Moesbach, 1930, p. 87). El paso de una etapa a otra se reconoce por el cambio del color de la madera: "Cambia la madera, después cuando llega a más maduro queda colorado, y es muy bonita madera del pellín. Mientras nuevo, blanquito no más", señala una persona del lago Neltume. El pellín también es reconocido por la dureza y durabilidad de su madera de color blanco-amarillento, la que es profusamente usada en construcción y carpintería, mientras que el hualle es usado para madera y leña. "El pellín dura más, al igual que las bases y techos de las casa", señala nuestro interlocutor del lago Neltume, lo que de paso explica que las construcciones, más que desaparecer con el paso del tiempo, cambien sus funciones. El roble, incorporado en la vida cotidiana bajo todas las formas imaginables, también se utiliza para la producción de instrumentos musicales: la pifilka -o silbato mapuche- y el pioko -pequeña flauta- (Hilger, 1957, p. 317) y su corteza para tintura de lana (Moesbach, 1930).

Las categorías generacionales con que se reconoce al roble son cruciales en el mundo mapuche donde se distingue entre los antiguos y los jóvenes, residiendo en los primeros la sabiduría. "Antes mandaban a un joven a conversar ahí para ir a sacar sabiduría, lo mandaban a hablar con los árboles". Abrazar a un pellín trae salud. Para desarrollar habilidades discursivas en los niños, según Hilger (1957, p. 81) “se les ordenaba pararse en el tronco de un roble chileno y hablar desde allí a los árboles, plantas y animales como si fueran seres humanos".

La presencia del roble en la vida ritual mapuche se hace evidente en tres instancias cruciales asociadas a la muerte: la primera en el tránsito hacia el mundo de los difuntos, la segunda en la construcción de esculturas conmemorativas y, la tercera, en la interlocución del difunto con el mundo de los vivos. En el tránsito a la muerte, que según Gay (1844, p. 277) es el pasaje de una vida de miseria a una de bienestar, el wampo o canoa mortuoria hecha de pellín es crucial. "Los echaban adentro de un tronco. Los dejaban en un árbol, cuando se morían, al tiro se balseaban tronco y allí echábamos 
la urna adentro... La urna tenía que ser de roble", se recuerda en Milleuco. El significado de esta urna es tan intenso que hasta hace poco tiempo los antiguos conservaban el tronco por ellos escogidos para su funeral. Pascual Coña narra que tras el fallecimiento "antes de todo hay que labrar la canoa y encajar en ella al muerto... Al otro día se juntan y se dirigen al bosque. Allí encuentran un grueso roble apellinado y se ponen a trozarlo. Cortado un trozo, empiezan a ahuecarlo a hachazos. Además labran una tapa para cubrir el cadáver" (Moesbach, 1930, p. 397). Mientras no se realice el entierro, el cuerpo del difunto es mantenido sobre una estera hecha de roble, la que se emplazaba sobre una hoguera de canelo cuyo humo permitía la preservación del cuerpo (Latcham 1909, p. 364).

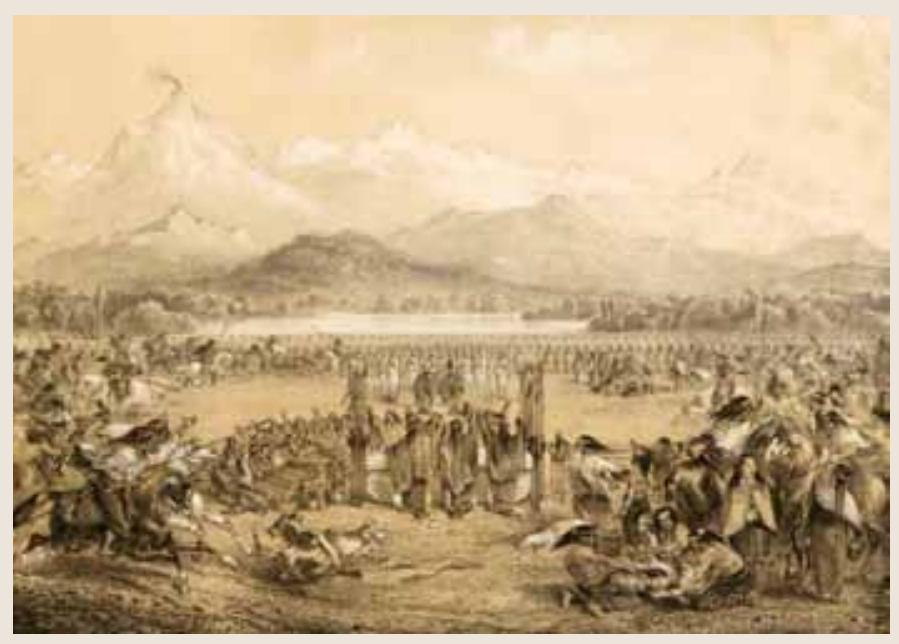

Figura 5. Entierro del cacique Cathiji en Guanegüe, mayo 1835. Atlas de la historia física y política de Chile / por Claudio Gay. París: En la Impr. de E. Thunot, 1854. 2 v. Biblioteca Nacional de Chile. (http://www.memoriachilena.cl/602/w3-article-98598.html).

La identificación con el Nothofagus obliqua alcanza su vínculo individual más estrecho en el paso de la vida a la muerte y su papel no es otro que el de ser acompañante material del difunto en su largo viaje al wenumapu (Grebe, 1993-1994). 


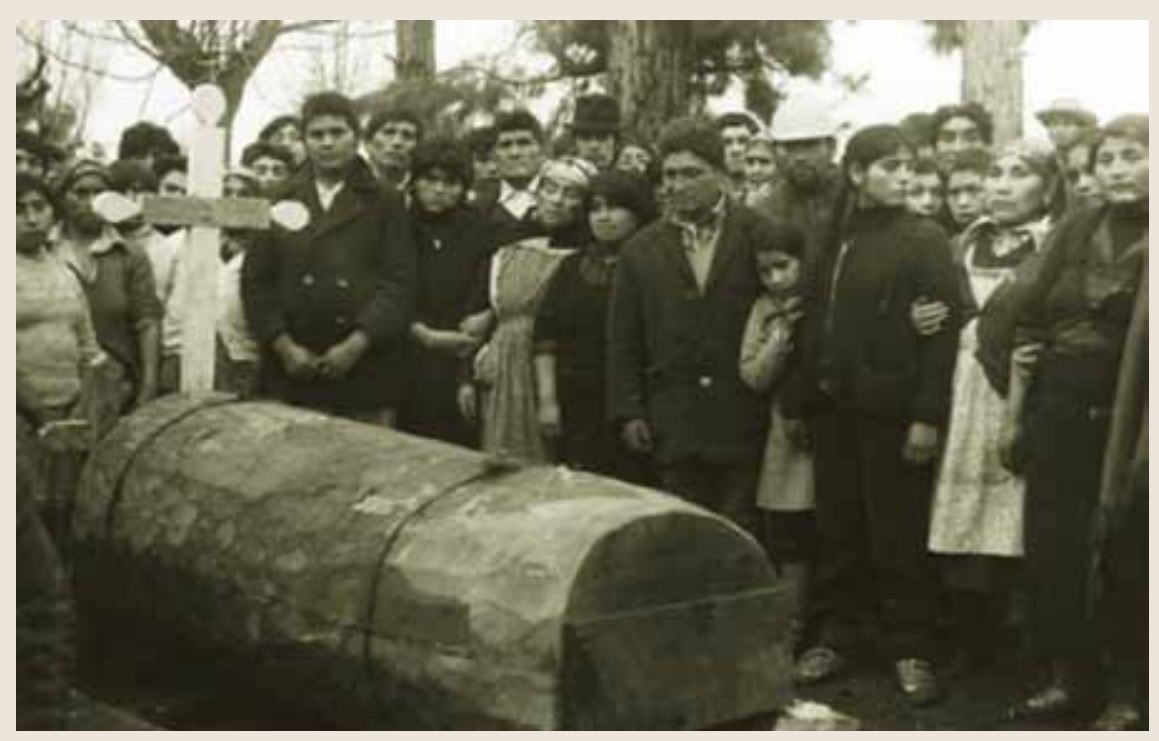

Figura 6. Funeral mapuche. Tomado de Visión Latente. (http://visionlatente.wordpress. com/wampo).

Así como en el mundo mapuche se reconocen diversos espíritus que se desprenden del viviente al momento de morir (Course, 2007), su presencia física se asocia a varios hitos recordatorios, siendo principal el chemamull o persona de madera de roble o de laurel, el cual se conserva en algunos cementerios indígenas del territorio. Pascual Coña los describe así:

Además habían hecho ya lo que llaman cruz, aunque no es cruz, sino solamente un palo en forma humana. Labran un grueso y duro trozo, esculpen la cara, la boca, las narices, los ojos, las orejas y los brazos: una figura del difunto. Al costado del palo labrado encajan un gran cuchillo, lo que quiere decir que este hombre era conocido como bravo y maloquero (Moesbach, 1930, p. 405).

La tercera forma en la que el roble aparece en la vida ritual asociada a la muerte es en la construcción de los descansos. Los descansos en el mundo mapuche-huilliche son pequeños altares erguidos en la memoria de las y los difuntos. La presencia de este simbolismo religioso denota, por una parte, una forma de articular los espacios cotidianos y sagrados, y, por otra, de separar lo comunitario de lo familiar: cuando se realiza la ceremonia, la urna pasa de manos de los familiares a manos de los miembros de la comunidad. Se sacrifica una gallina y se gira el féretro, de modo que la cabeza del 
difunto dirija el cortejo una vez salido del predio familiar (Alvarado y Mera 2004; Skewes, Guerra, Rojas, \& Mellado, 2011).

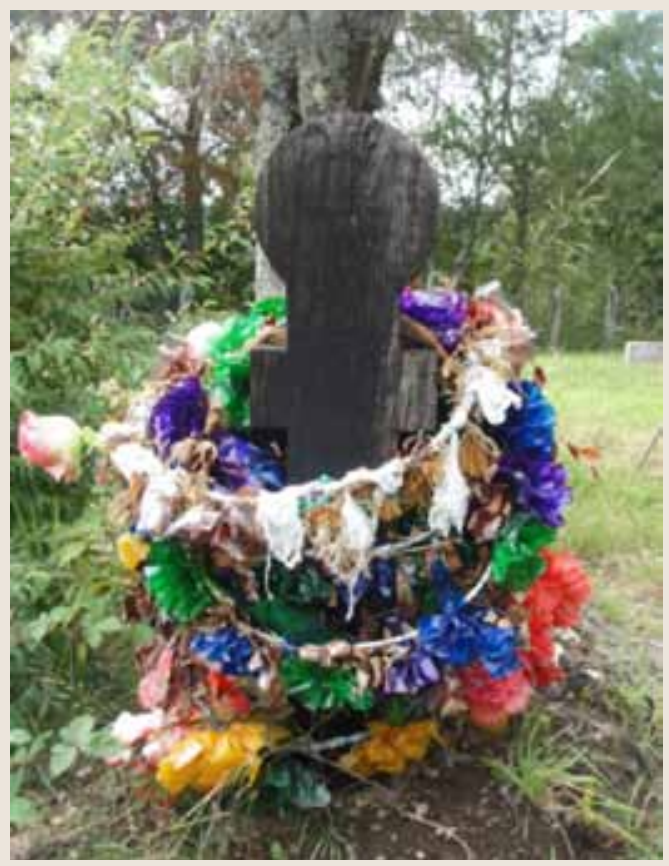

Figura 7. Un chemamull (fotografía de P. Rojas).

La arquitectura de los descansos adopta la forma de un casa o alero de menos de un metro de altura ornamentado con una cruz y dispuesto a los pies de un árbol, de preferencia un pellín (Nothofagus obliqua). El sitio escogido como descanso es elegido por la familia o está estipulado con anterioridad por la misma persona. Algo común a la mayoría de los descansos es que se sitúan bajo la sombra de un roble y, en algunos casos, lo único que se constituye como descanso es el árbol.

El descanso se construye en relación al espíritu de la persona, el que puede volver al mundo de los vivos. En la cultura mapuche, el espíritu se distingue del alma y la persona está constituida por diversos componentes espirituales, siendo el espíritu que puede merodear en las casas gimiendo, haciendo sonar las cosas o provocando fuegos dentro de la ruka (Course, 2007). La construcción que se hace en memoria del difunto termina por derruirse y finalmente sólo queda el árbol en su memoria y, en tanto tal, es usado por la comunidad como una señal para describir el territorio. 


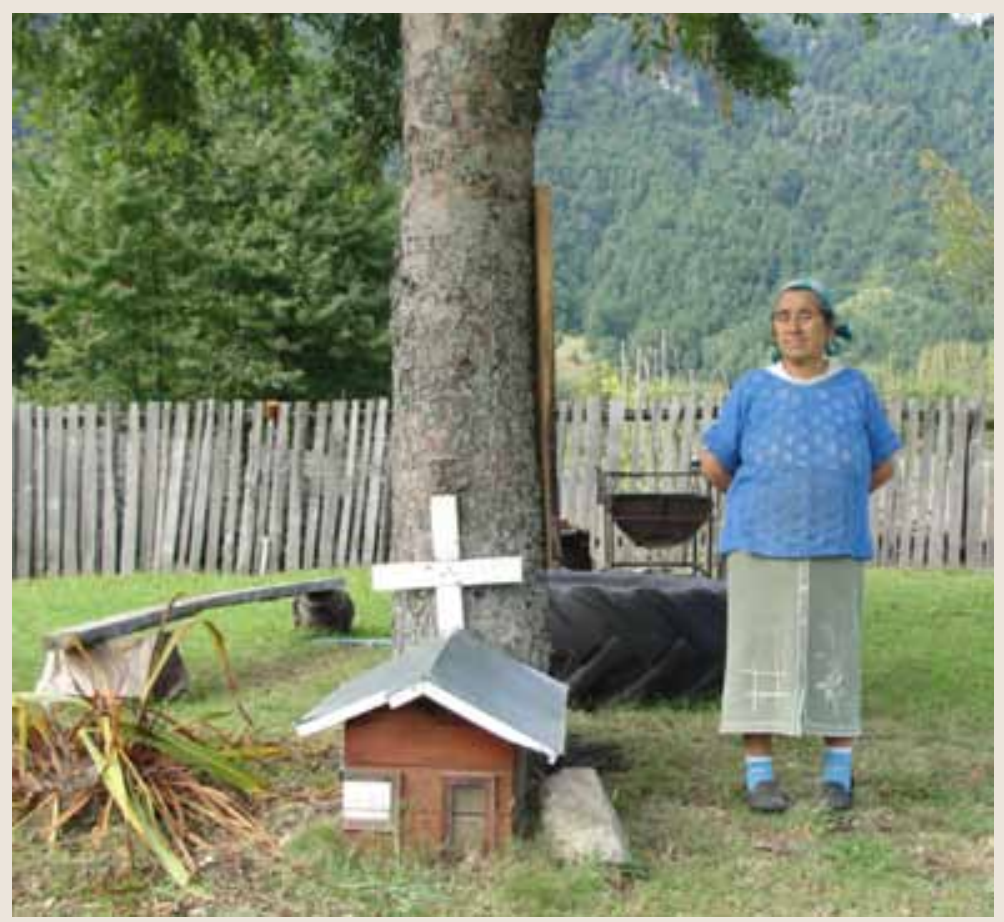

Figura 8. Un descanso (fotografía P. Rojas).

Los árboles, en este sentido, fijan la geografía social del paisaje, de modo que cada lugareño o lugareña era capaz de identificar las diversas posiciones en el territorio sobre la base de estos referentes arbóreos. "Los árboles son como las personas, nuestros hijos, los adoramos", nos señala una vecina de Milleuco. "Los antiguos tenían respeto por los árboles porque pensaban que era un árbol vivo. Los árboles también tienen sus longko, principalmente el pellín", ratificando, de paso, la existencia que María Ester Grebe (2000) describiera acerca de los ngen-walle, espíritus tutelares del bosque de robles. El árbol se constituye en presencia cotidiana de los difuntos, en parte de la memoria ambiental de la comunidad y su obstinada persistencia da cuenta de las sucesiones generacionales a través de las que se reproduce la cultura mapuche cordillerana. "No se oye tu voz de alma de roble", reclama a los peñi o mapuche el poeta Ponciano Rumián (1996). 


\section{CONCLUSIONES}

El paisaje es fruto de una historia en la que no cabe deslindar la acción humana de la acción de otras especies o de los elementos. El paisaje, cualquiera sea el momento en que se le describa, corresponde al estado actual de las relaciones entre seres humanos y no humanos. El paisaje encarna visiones de mundo, intereses comerciales y prácticas técnicas, instrumentales y rituales. Los ejemplos europeos son elocuentes: el pino navideño, la creación de cotos de caza y la domesticación de especies maderables dan cuenta de profundas transformaciones del paisaje asociadas a prácticas religiosas, sociales y políticas. De aquí que las formas de los paisajes, las especies que los constituyen, el emplazamiento material de la residencia humana merezcan ser concebidas como una síntesis que revela historias que no siempre alcanzan a ser escritas o contadas. Los árboles son parte integral del paisaje y sirven de armazón tanto material como simbólica para el ensamblaje de los seres humanos con su naturaleza circundante. Sin embargo, el que la cultura española fuese, como magistralmente la describiera Elizalde (1968), silvofóbica, puso en riesgo no sólo la existencia de los bosques sino también la comprensión de los procesos culturales de pueblos de tradiciones culturales diversas. No debiera extrañar, en este sentido, que en los textos acerca de la sociedad mapuche no haya mayores referencias al roble ni a las voces que los designan. El árbol pareciera no existir para el observador externo y, sin embargo, como aquí se muestra, la urdiembre más íntima del ser mapuche pareciera estar inexorablemente atada a las especies arbóreas y, en forma muy especial, al Nothofagus obliqua, especie a la que se asocia el ser humano y que le acompaña tanto en lo cotidiano como en lo trascendente.

La presencia del roble es, hemos sugerido aquí, decisiva en lo cotidiano no sólo como soporte material de vida sino como medio de identificación individual y familiar. La descripción que Ricardo Latchman da de la vigilia que precede al funeral es significativa toda vez que el difunto es acomodado en un marco hecho de roble a la vez que le envuelve el humo del fuego del canelo. Las dos especies dan cuenta de las dimensiones cotidianas, la una, y trascendente, la otra. Así como el canelo y el laurel son las que mejor se asocian a las prácticas religiosas, el Nothofagus es, por excelencia, la especie que mejor vincula la cultura con lo cotidiano. Es en la muerte donde se precisa la relación del árbol con los seres humanos que a través suyo se hacen representar sea por medio de la urna que les acompaña en su viaje final, sea como la imagen que les representa en los cementerios, sea como parte de la gruta donde pueden mantener sus vínculos con los descendientes. 
¿Cuánto de arbitrario hay en la elección de un determinado referente simbólico? No es del caso resucitar esta vieja discusión pero tampoco convendría eludir fácilmente las propiedades de una especie a la hora de entender su incorporación al mundo de los humanos. Y en el roble parecieran estar radicadas una buena parte de las características con las que mejor se describe a la cultura mapuche. El carácter milenario del árbol, su resiliencia frente a las catástrofes, la agrupación de sus flores masculinas y femeninas, la dureza de su madera, su durabilidad, son algunas de tales características. Aunque inconveniente pudiera parecer a las miradas constructivistas, tal vez haya que seguir prestando atención a la materialidad de la existencia humana y reconocer allí los procesos de co-optación de la naturaleza que mejor se han prestado de una supervivencia basada en el ejercicio práctico y la transformación de las cosas según fines diversos a los que le pudieron haber sido propios. Las propiedades percibidas de cada elemento parecieran ser decisivas en cuanto a su incorporación al repertorio social, ritual y económico.

Independientemente de los fundamentos de su elección, las especies escogidas como identitarias son las que se incorporan en los repertorios culturales como el mejor reflejo de la condición humana. Al mismo tiempo, su ritualización permite no solo transustanciar la condición humana en la no humana sino que también preservar de mejor modo esas especies. La ecología local reclama ritos que permitan al modo de las quebradas proteger especies que, de lo contrario, se vuelven presa de la depredación inmisericorde de la explotación comercial.

Muy lejos está la concepción mapuche del árbol de lo que la mirada chilena ve en él. Las roblerías de las montañas de Vichuquén, nos recuerda Elizalde (1968), fueron devastadas: las mejores maderas del país terminaron sirviendo como durmientes para las líneas férreas. Y así sucedió con buena parte del bosque chileno. La voracidad comercial no fue ajena a las propias comunidades mapuche las que también fueron llevadas a creer que los robles eran dinero y, en los sesenta del siglo pasado, no fueron pocas las hectáreas taladas en las comunidades.

La revitalización de las culturas originarias permite iniciar nuevos diálogos en torno de la naturaleza, diálogos que tienen la virtud de hacer confluir la sabiduría local con la poesía, las ciencias sociales y las ciencias naturales. Así como el roble, hay otras especies -el mañío, la luma, el coihue, el temu, el ñirre- que esperan ser descubiertas en su silenciosa infiltración en los tejidos sociales de la cultura mapuche. $\mathrm{Y}$ otro tanto ocurre al otro 
lado de la divisoria cultural donde se multiplican los plátanos orientales, las araucarias brasileñas, las palmeras y las orquídeas.

\section{AGRADECIMIENTOS}

El presente artículo es producto de los proyectos de investigación Fondecyt F-1090465: "Los Paisajes del Agua" y F-1120139: "La Impronta Andina en el Sistema Religioso Cosmovisionario Mapuche Williche". Quisiéramos agradecer a las personas de las comunidades del lago Neltume y de Milleuco por su colaboración desinteresada en nuestro trabajo y a Pablo Rojas Bahamonde, estudiante de Antropología de la Universidad Austral de Chile, cuyo trabajo de campo resultó crucial para comprender las dinámicas que aquí se discuten. También se agradece la desinteresada dedicación de quien revisara este artículo en el proceso editorial.

\section{REFERENCIAS}

Alarcón, M. (1958). Panguipulli: El pueblo y la comuna. Tesis (Profesor Primario). Loncoche: Universidad Católica de Chile.

Alvarado, M. y Mera, R. (2004). "Estética del paisaje y reconstrucción arqueológica. El caso de la región del Calafquén (IX y X Región-Chile)". Chungara, Revista de Antropología Chilena, Volumen especial, 559-568.

Armstrong, N. (2008). "England and German Christmas Festlichkeit, c.18001914”. German History, 26(4), 486-503.

Course, M. (2007). “Death, biography and the Mapuche person”. Ethnos, 72(1), 77-101.

Donoso, C. (1993). Bosques templados de Chile y Argentina. Santiago: Editorial Universitaria.

Donoso, C. (2007 [2005]). Árboles nativos de Chile. Santiago: Marisa Cuneo.

Eliade, M. (1979). Imágenes y símbolos: Ensayos sobre el simbolismo mágicoreligioso. Madrid: Taurus.

Elizalde, R. (1968). La sobrevivencia de Chile. Santiago: Ministerio de Agricultura, Servicio Agrícola y Ganadero, El Escudo Impresores.

Garibaldi, A. y Turner, N. (2004). "Cultural keystone species: Implications for ecological conservation and restoration". Ecology and Society, 9(3), 1. Recuperado el 30 de abril de 2012, de http://www.ecologyandsociety.org/vol9/ iss $3 /$ art 1

Gay, C. (1844). “Épisode sur l'enterrement du cacique Cathiji dans l'Araucanie”. Bulletin de la Société de géographie, 30, 268-282. 
Grebe, M. E. (1993-1994). "El subsistema de los ngen en la religiosidad mapuche". Revista Chilena de Antropología, 45-64.

Grebe, M. E. (2000). "Relaciones hombre/naturaleza en la cultura mapuche. Los Ngen: sus implicancias y proyecciones socioculturales”. IX Jornada de Alternativas Religiosas en América Latina, (pp. 1-8). Buenos Aires.

Grosse, H.; Larraín, Ó. y Mujica, R. (2007). "Valorización de los bosques de segundo crecimiento para los tipos forestales roble-raulí-coigüe y coigüe, raulí-tepa”. Ciencia e Investigación Forestal, 13(2), 371-384.

Guerra, D.; Barrientos, M. y Ramírez, V. (1999). Las Ñañas. Santiago: Lom.

Heads, M. (2006). "Panbiogeography of Nothofagus (Nothofagaceae): analysis of the main species massings". Journal of Biogeography, 33, 1066-1075.

Hilger, I. (1957). Araucanian child life and its cultural background. Washington: Smithsonian lnstitution.

Klubock, T. M. (2011). "The nature of the frontier: forests and peasant uprisings in southern Chile". Social History, 36(2), 121-142.

Krotz, E. (2004). La otredad cultural: entre utopía y ciencia. Un estudio sobre el origen, el desarrollo y la reorientación de la antropología. México: FCE.

Lara, A.; Solari, M.; Prieto, M. y Peña, M. (2012). "Reconstrucción de la cobertura de la vegetación y uso del suelo hacia 1550 y sus cambios a 2007 en la ecorregión de los bosques valdivianos lluviosos de Chile (35 - 43 $\left.30^{\prime} \mathrm{S}\right)$ ". Bosque, 33(1), 13-23.

Latcham, R. (1909). Ethnology of the Araucanos. Londres: Royal Anthropological lnstitute of Great Britain and Ireland.

Loveman, B. y Lira, E. (2001). Las ardientes cenizas del olvido: Via chilena de reconciliación política,. Santiago: Lom, Dibam.

Lyn G., C. \& Michael D., C. (2005). "Not so ancient: the extant crown group of Nothofagus represents a post-Gondwanan radiation". Proceedings of the Royal Society of Biology, Biological Sciences, 272(1580), 2535-2544.

Marx, K. (1984). El capital. México: Siglo XXI.

Marx, K. y Engels, F. (2005). La ideología alemana. Buenos Aires: Santiago Rueda.

Moesbach, E. W. (1930). Vida y costumbres de los indígenas araucanos de la segunda mitad del siglo XIX. Santiago: Imprenta Cervantes.

Neira, E. (2012). Flora Chilena. Recuperado el 31 de enero de 2013, de http:// www.florachilena.cl/Tipos_Forestales/Roble-Rauli-Coihue/Distribucion. htm

Olivares, J. C. (2010). Las techumbres de la garúa: El sentido de lo propio en los discursos de la arquitectura de lo sur. Tesis doctoral. Doctor en Ciencias Humanas. Valdivia, Universidad Austral de Chile.

Parachin, V. M. (2012). “The Christmas tree. An ancient tradition”. The Priest, 50-51.

Pogue, R. (1992). Forests: the shadow of civilization. Chicago: University of Chicago Press. 
Read, J. \& Hill, R. (1985). "Photosynthetic Responses to Light of Australian and Chilean Species of Nothofagus and their Relevance to the Rainforest Dynamics". New Phytol, 101, 731-742.

Rehren, O. (1908). Memoria de la Inspeccion Jeneral de Colonizacion e Inmigracion. Santiago: Imprenta i Encuadernacion de S. A. Garcia Valenzuela.

Rivas, R. (2006). Desarrollo Forestal de Neltume: Estado y Trabajadores (19241990). Tesis de Grado (Profesor de Estado en Historia). Valdivia: Universidad Austral de Chile.

Rumián, P. (1996). Cancionero Wechemapu. El Canto Joven de la Tierra. Santiago: CONADI.

Scott, J. C. (1998). Seeing like a State.How Certain Schemes to Improve the Human Condition Have Failed. New Haven y Londres: Yale University Press.

Skewes, J. C.; Guerra, D.; Rojas, P. y Mellado, M. (2011). “¿La memoria de los paisajes o los paisajes de la memoria?". Desenvolvimento e Meio Ambiente (Editora UFPR), 23, 39-57.

Solari, M. E.; Cueto, C.; Hernández, F.; Rojas, J. y Camus, P. (2011). "Procesos territoriales y bosques en la Cuenca del Río Valdivia (siglos XVI-XIX)”. Revista de Geografía Norte Grande, 49, 45-62.

Somers, R. (1848). Letters from the Highlands; or, the Famine of 1847. Londres: Marshall Simpkin.”

Swenson, U.; Hill, R. \& McLoughin, S. (2001). "Biogeography of Nothofagus Supports the Sequence of Gondwana Break-up”. Taxon, 50(4), 1025-1041.

Turner, V. (1999). La selva de los símbolos. México: Siglo XXI. 